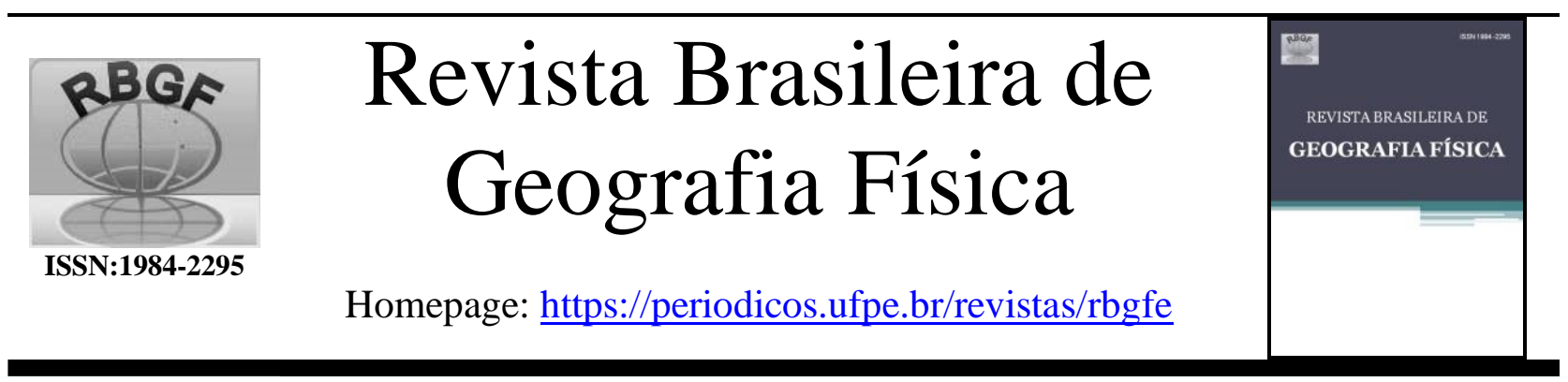

\title{
Usos múltiplos da água por usuários outorgados nas bacias hidrográficas dos Rios Aguapeí e Peixe
}

\author{
Fernanda Buono da Silva ${ }^{1}$, Timóteo Ramos Queiroz ${ }^{2}$, Denilson Burkert ${ }^{3}$, Rodrigo Lilla Manzione ${ }^{4}$
}

\begin{abstract}
${ }^{1}$ Mestranda. UNESP (Universidade Estadual Júlio de MesquitaFilho) - FCE (Faculdade de Ciências e Engenharia) - Campus de Tupã. Curso de PósGraduação em Agronegócio e Desenvolvimento. Rua Domingos da Costa Lopes, 780, CEP 17602-496, Tupã, São Paulo. (14) 3404-4200. buonoambiental@ hotmail.com. ${ }^{2}$ Professor Associado. UNESP (Universidade Estadual Júlio de Mesquita Filho) - FCE (Faculdade de Ciências e Engenharia) - Campus de Tupã. Departamento de Administração. Rua Domingos da Costa Lopes, 780, CEP 17602 -496, Tupã, São Paulo. (14) 34044200. timoteo.queiroz@unesp.br. 3Pesquisador Científico da Agência Paulista de Tecnologia dos Agronegócios - APTA Regional Alta Paulista denilson.burkert@sp.gov.br. ${ }^{4}$ Professor Associado. UNESP (Universidade Estadual Júlio de Mesquita Filho) - FCE (Faculdade de Ciências e Engenharia) - Campus de Tupã. Departamento de Engenharia de Biossistemas. Rua Domingos da Costa Lopes, 780, CEP 17602-496, Tupã, São Paulo. (14) 3404-4200. lilla.manzione@ unesp.br.
\end{abstract}

Artigo recebido em 30/09/2020 e aceito em 25/04/2021.

\section{R E S U M O}

A demanda crescente por recursos hídricos pode gerar conflitos entre diferentes usuários. Para tal, foram implantados instrumentos de gestão de recursos hídricos, em especial a outorga de direito de uso, que priorizar os usos múltiplos e racionalda á gua. O trabalho foi realizado com o objetivo de analisaro perfil e a distribuição dos usos de á gua outorga dos em relação aos a spectos socioeconômicos nos municípios que compõem o Comitê das Bacias Hidrográficas dos Rios Agua peí e Peixe (CBH-AP). Foram a na lisados dados de outorgas de 58 municípios com dos quais foi elabora da esta tística descritiva para a discussão sobre o cenário dos usos múltiplos da água outorgados. Posteriormente os dados foram submetidos à análise estatística de regressão múltipla, na qual foi analisada a relação entre o número de outorgas por município e seus respectivos parâmetros socioeconômicos. Os resultados demonstraram as outorgas nos municípios que compõem a área de abrangência do Comitê das Bacias Hidrográficas dos Rios Aguapeí e Peixe estão relacionadas principalmente a o uso de á guas subterrânea s em áreas rurais. Nos três municípios (Bastos, Dracena e Tupã) concentram $26 \%$ da s outorga s a na lisa das. O aumento IDHM e da população, concomitantemente, estimula m o crescimento do número de outorgas. Com isso, verifica-se a necessidade de implementação de políticas públicas que colaborem direta ou indiretamente para o aumento da regularização do uso da á gua.

Palavras-chave: Recursos Hídricos; Água Doce; Governança da Água; Oeste Paulista; Políticas Públicas.

\section{Multiple uses of water by users granted in the hydrographic basins of the Aguapeí and Peixe rivers}

\begin{abstract}
A B S T R A C T
The growing demand for water resources can generate conflicts between different users. To this end, water resources management instruments were implemented, in particular the granting of the right to use, which prioritize the multiple and rational use of water. The work was carried out with the objective of analyzing the profile and the distribution of water uses granted in relation to socioeconomic aspects in the municipalities that make up the Hydrographic Basins Committee of the Aguapeí and Peixe Rivers (CBH-AP). Grant data from 58 municipalities with which descriptive statistics were analysed and prepared for the discussion on the scenario of the multiple uses of water granted. Subsequently, the data were given to the multiple regression statistical analysis, in which the relationship between the number of grants per municipality and its socioeconomic parameters was analyzed. The results demonstrated the grants in the municipalities that comprise an area covered by the Hydrographic Basins Committee of the Aguapeí and Peixe rivers are mainly related to the use of groundwater in rural areas. In the three municipalities (Bastos, Dracena and Tupã) concentrate $26 \%$ of the analyzed grants. The increase in MHDI and population, at the same time, stimulates the grow th in the number of grants. Thus, there is a need to implement public policies that collaborate directly or indirectly to increa se the regularization of water use.
\end{abstract}

Keywords: Water resource; Freshwater; Water governance; São Paulo western; Streamflow region alization; Public Policy. 


\section{Introdução}

A água representa o recurso natural de maior importância para o planeta sendo necessário para a manutenção da biodiversidade e está presente em qualquer atividade humana Grizzetti et al. (2016). De acordo com Santos et al. (2018) esse recurso é essencial para o desenvolvimento econômico da população, representa o principal constituinte dos seres vivos e um componente da paisagem e do meio ambiente. Comocaracterística a água apresenta potencial para ser utilizada em diversos fins, como abastecimento urbano, dessedentação de animais, agricultura, indústria, dentre outros.

Ao longo dos últimos anos pressões cada vez maiores sobre os recursos têm surgido e no futuro esse cenário deve se intensificar ainda mais. Segundo UNESCO (2015) até 2050 ocorrerá um avanço na demanda hídrica mundial de 55\% que será gerado pelo setor industrial, sistemas de geração de energia termoelétrica e os usuários domésticos, os quais estão sofrendo crescente demanda.

A utilização da água de forma desordenada pode desencadear a concorrência por sua disponibilidade, além de causar danos ao meio natural no que tange a qualidade e quantidade, permitindo, dessa maneira o surgimento de conflitos por seu uso, caso não seja gerenciada corretamente. As atividades dos usuários de água em uma bacia hidrográfica são competitivas e se acirram à medida que diminui a disponibilidade hídrica. Dessa maneira, ao longo do tempo a competição pela água tende a gerar conflitos entre usos e usuários e as desigualdades nos acessos aos serviços, impulsionando fortes impactos nas economias locais e no bem-estar humano. Assim, a gestão sustentável dos recursos hídricos é um desafio quando uma região sofre com a escassez e experimenta uma crescente demanda antrópica por água Hassan et al. (2017) e como descrito por Calado et al. (2020) o ordenamento do uso da água se torna primordial para combater conflitos que envolvam os usos múltiplos da água.

Em virtude disso as políticas de recursos hídricos têm evoluído buscando a inserção de ferramentas que permitam o melhor ordenamento do uso da água, entre elas, a outorga do direito do uso da água. Segundo Piazi et al. (2018) a outorga aparece, neste cenário, como ferramenta no intuito de inibir o uso indiscriminado da água, de forma a assegurar aos usuários, o direito de uso da água, bem como seus usos múltiplos.

No Estado de São Paulo a promulgação da Constituição Estadual de 1989 determinou um momento importante para a questão do gerenciamento dos recursos hídricos. Foi a partir dela que foi instituído o sistema integrado de gerenciamento dos recursos hídricos (SIGRH) o qual deveria, a partir daquele momento, buscar a proteção das águas contra ações que pudessem comprometer o seu uso atual e futuro. Nesse novo conjunto de normas que regem os recursos hídricos no Estado foi apresentada a outorga de direitos do uso das águas, instrumento de gestão que trata da aprovação prévia por organismos estaduais de controle ambientale de gestão de recursos hídricos, na forma da lei, dos atos de que possam influir na qualidade das águas superficiais e subterrâneas. Assim sendo, a outorga se torna necessária para a devida implantação de qualquer intervenção que venha alterar o regime, a quantidade ou a qualidade do corpo de água.

$\mathrm{O}$ ato da outorga deve garantir, ao usuário, o direito do uso do recurso hídrico, condicionandoa à disponibilidade hídrica a ser explorada, de forma que o processo administrativo a qual a autorização está submetida seja capaz de registrar as condições de intervenção do recurso hídrico e características do usuário que a pleiteia. Dessa maneira a outorga representa além de um instrumento de gestão também uma ferramenta de informação na medida em que um banco de dados pode ser gerado a partir das informações a respeito da localização e do perfil do uso da água realizado.

Atualmente, o órgão que tem a atribuição de administrar e outorgaro uso daságuas no Estado é o Departamento de Águas e Energia Elétrica (DAEE). Em 1994, por meio da Lei no 9.034, o território do Estado foi dividido em 22 Unidades Hidrográficas de Gerenciamento de Recursos Hídricos (UGRHI), divididas dessa maneira em função de critérios hidrológicos, políticos, socioeconômicos e institucionais. As UGRHI's referem-se a grandes regiões hidrográficas que partilham de um curso d'água principal e são unidades territoriais "com dimensões e características que permitiam e justificavam o gerenciamento descentralizado dos recursos hídricos" (SÃO PAULO, 1991. Art.20).

Segundo Rocha e Santos (2018) as bacias hidrográficas dos rios Aguapeí e Peixe localizamse na porção Oeste estado de São Paulo entre as coordenadas -49.395142 ; e -52.168376, longitude Oeste e $-20.951768 ;-22.439189$, latitude Sul. Por apresentarem algumas semelhanças nos aspectos geográficos, físico e socioeconômico, as Unidades de Gerenciamento dos Recursos Hídricos (UGRHI) dos rios Aguapeí (UGRHI 20) e Peixe (UGRHI 21) foram inseridas em um único Comitê 
de Bacias Hidrográficas, conforme Lei estadual $\mathrm{n}^{\circ}$ 7.663 de 30 de dezembro de 1991 ambas são geridas pelo Comitê das Bacias Hidrográficas dos rios Aguapeí e Peixe (CBH-AP).

Diante do contexto, o presente trabalho foi desenvolvido com o objetivo de analisar o perfil e a distribuição dos usos de água outorgados em relação aos aspectos socioeconômicos dos municípios participantes do comitê das bacias hidrográficas dos rios Aguapeí e Peixe (CBH-AP).

\section{Material e Métodos}

Área de estudo

A abrangência do estudo compreendeu os territórios pertencentes aos municípios que compõem o Comitê das bacias hidrográficas dos rios Aguapeí e Peixe, sendo essas bacias identificadas pelo Sistema de Gerenciamento de Recursos Hídricos do Estado de São Paulo como UGRHI's números 20 e 21, respectivamente (Figura 1). As duas UGRHI's apresentam um total de $23.965 \mathrm{~km}^{2}$, juntas são compostas por 58 municípios e detém um total de 806.692 habitantes (CBH-AP, 2016).

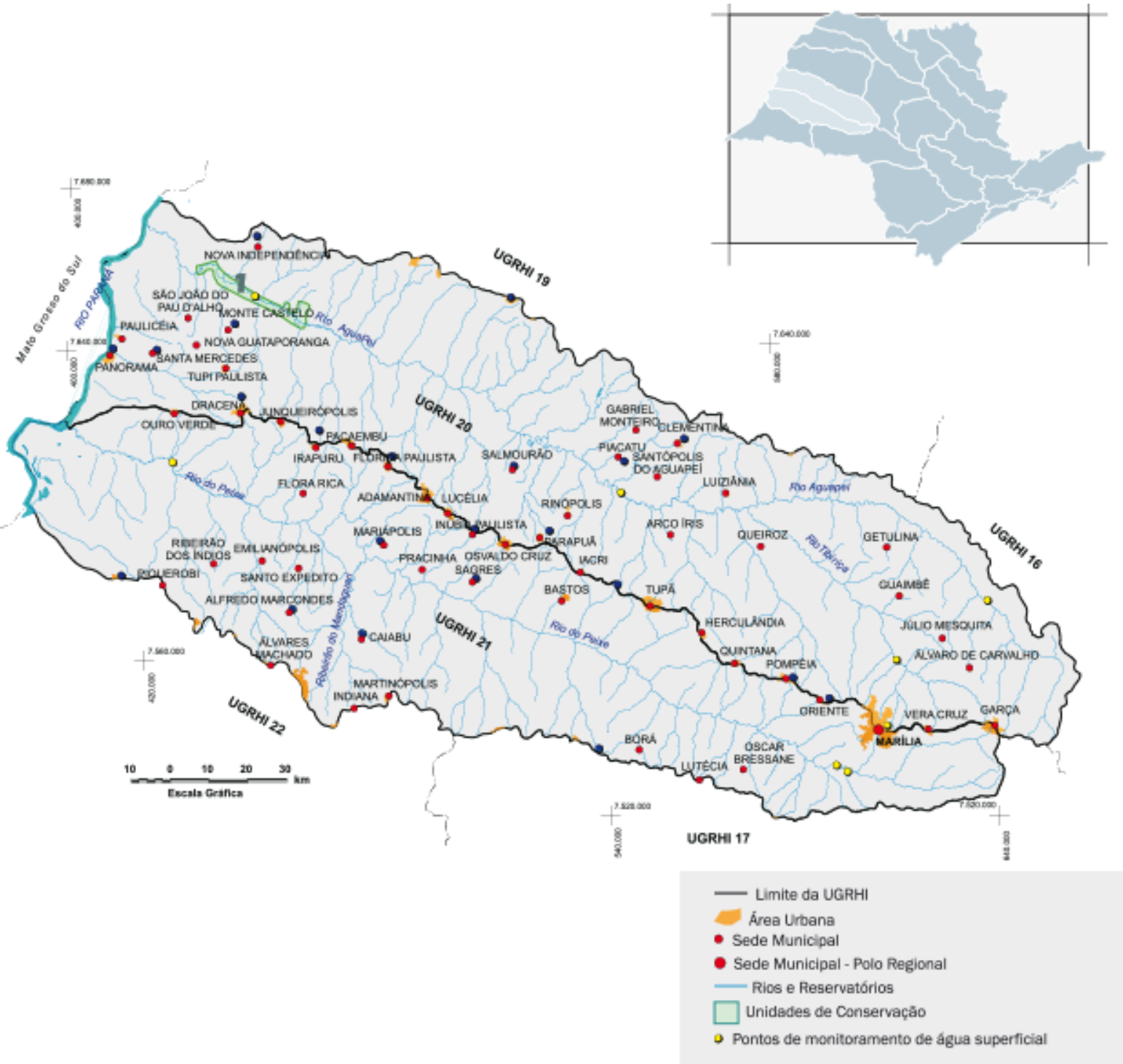

Figura 1. Descrição das Unidades de Gerenciamento de Recursos Hídricos do Estado de São Paulo números 20 e 21, respectivamente Aguapeí e Peixe. Fonte: SIGRH, 2020.

As principais atividades econômicas desenvolvidas nos centrosurbanos dessas unidades são os serviços e comércio, com exceção da cidade de Marília, onde se concentra grande parte das atividades industriais, principalmente relacionadas

ao departamento alimentício. Já nas áreas rurais as atividades que mais se destacam são a pecuária e 
agricultura com as lavouras de café, cana-deaçúcar e milho. Também são praticadas as atividades de extração mineral de areia nos afluentes do rio Aguapeí e olarias, principalmente nos municípios que margeiam o rio Paraná (SIGRH, 2020).

A coleta dos dados foi realizada no dia 26 de junho de 2019 gerando uma amostra total de 51 municípios, sendo 31 municípios representantes da UGRHI-20 e 20 municípios representantes a UGRHI-21.

De acordo comesse espaço amostral foram obtidos dados que puderam determinar o número total de usuários cadastrados por município. A seguir, de cada usuário em cada município, foram colhidos os dados sobre as características: finalidade de uso; uso; usuário; situação administrativa. Essa classificação foi utilizada de acordo com a nomenclatura utilizada pelo DAEE.

Foram desconsiderados para a análise os dados relativos à "situação administrativa" quando se encontravam sem informações, além desses, foram também desconsiderados dados quando descritos como "requerimento indeferido", "excluído" e "desativado".

\section{Análise Estatística}

Os dados foram tabulados em planilha eletrônica e submetidos à análise estatística descritiva com se buscando analisar o perfil dos usuários e a distribuição das outorgas por município na área de abrangência do CBH-AP.

Também foi realizada análise de regressão linear múltipla entre os valores do número total de outorgas em cada município e suas próprias características socioeconômicas de forma a se buscar identificar funções que pudessem demonstrar as suas respectivas relações.

Os valores referentes aos parâmetros socioeconômicos dos diferentes municípios foram obtidos a partir da plataforma online do Instituto Brasileiro de Geografia e Estatística (IBGE), sendo:

- Índice de Desenvolvimento Humano Municipal (IDH-M) referente ao censo do ano de 2010; - Produto Interno Bruto per capita (PIB) referente ao censo do ano de 2016;

- Área em km² referente ao censo do ano de 2018; - População referente ao censo do ano de 2010.

Os respectivos dados foram organizados em tabelas no software Microsoft Office Excel $®$ e anexados na ferramenta de análise estatística Minitab ${ }^{\circledR}$ para a aplicação da técnica de regressão linear múltipla na qual a variável dependente (resposta) foi definida como número de atividades outorgadas e os valores dos parâmetros socioeconômicos forma considerados como variáveis independentes. O modelo da equação foi elaborado de acordo com Gazola (2002), Montgomery e Runger (2008) e Morettin e Bussab (2012) descrito como:

$$
\mathrm{Y}=\beta_{0}+\beta_{1} \mathrm{x}_{1}+\beta_{2} \mathrm{x}_{2}+\ldots+\beta_{\mathrm{k}} \mathrm{x}_{\mathrm{k}}+\varepsilon
$$

Onde Y significa a variável dependente, os $\mathrm{X}$ 's são as k-ésimas variáveis independentes; $\beta_{\mathrm{j}} \mathrm{o}$ coeficiente de regressão linear, sendo $\mathrm{j}=0,1, \ldots, \mathrm{k}$. $\mathrm{O}$ termo $\varepsilon$ indica o erro aleatório.

Os dados obtidos foram log-transformados (base dez), buscando se linearizar as relações e reduzir o efeito de valores elevados, assim como descrito por Nunes et al. (2019), visando atender o quesito da linearidade. Dessa maneira foi possível se obter resultados satisfatórios quanto à assimetria das variáveis independentese dependente. A seguir foi aplicado o método de seleção dos melhores subconjuntos “Best Subsets Regression”o qual foi realizado com vistas a escolher o modelo mais adequado levando-se em conta um número de variáveis independentes suficientes para a elaboração do próprio modelo. A seleção do melhor subconjunto é um modo eficiente de constatar os modelos com o menor número possível de variáveis e que se ajustam adequadamente aos seus dados. O subconjunto de variáveis de um modelo pode estimar os coeficientes de regressão e anunciar futuras respostas com menores variações do que o modelo que inclui todas as variáveis (MINITAB, 2019).

As estatísticas usadas para avaliar e comparar os diferentes modelos de regressão obtidos foram os valores de $\mathrm{R}^{2}$ ajustado e a estatística C-p de Mallows. Consideram-se bons modelos com maior valor de $\mathrm{R}^{2}$ ajustado e menor valor de $\mathrm{Cp}$. Foi utilizado o nível de significância das variáveis de $5 \%$ e sincronizado com o valor $p$. A adequação do modelo foi também submetido a análise de resíduos e estatísticas de ajuste, como o coeficiente de determinação ajustado $\left(\mathrm{R}^{2}\right)$.

\section{Resultados e discussão}

\section{Perfil do uso da água}

Os dados utilizados na pesquisa foram os disponibilizados publicamente no sistema de outorgas do DAEE os quais são gerados a partir das informações contidas nas solicitações dos diferentes usuários e, até então, submetidas de forma analógica ao órgão outorgante. No entanto, esse sistema se encontra em fase de substituição pelo chamado Sistema de Outorga Eletrônica (SOE) com o qual se pretende simplificar e automatizar os procedimentos de outorga de direito de uso e intervenções sobre os recursos hídricos no 
Estado de São Paulo. Dessa maneira, o abastecimento do SOE com informações ainda é recente, acarretando em um baixo volume de dados. A transferência dos dados do sistema analógico para o sistema eletrônico com seu respectivo abastecimento deverá ocorrer de forma paulatina na medida em que novas concessões e as renovações de concessões já existentes sejam solicitadas ao órgão.

Em relação à região por onde se distribuem os municípios que compõem o CBH-AP, essa é abastecida por fontes de água superficiais, ou seja, pelos rios Aguapeí e Peixe. Mas, a maior parte do fornecimento de água para as cidades nessa região é proveniente de fontes subterrâneas, nesse caso, pelos aquíferos Bauru, Serra Geral e Guaraní, sendo, dentre esses, o primeiro o mais utilizado e apresentando três unidades: Formação Marília a Leste, Formação Santo Anastácio e Formação Adamantina a Oeste, com predominância desta última (Godoy, 1999).

Segundo CBH-AP (2020) a disponibilidade de água per capita determinada pela vazão média em relação à população total referente ao ano de 2017 é considerada boa, apresentando $6.927,77 \mathrm{~m}^{3} / \mathrm{hab}$.ano. Nesse caso pode se observar que a oferta de água na região ainda não se encontra ameaçada em virtude dos usos praticados garantindo assim capacidade de oferta a qual poderá colaborar com o desenvolvimento regional em função do possível aumento na exploração do recurso no futuro.

De acordo comos dados obtidos (Tabela 1) que dentre os usos a captação subterrânea apresenta $50,99 \%$ dos registros, sendo o uso mais expressivo, seguido de lançamentos em solo com 16,76\% do total, enquanto que os demais usos apresentam participações de menor expressão. Em relação aos tipos de usuários outorgados na área do $\mathrm{CBH}-\mathrm{AP}$ pode se verificar que os cinco principais representam $77 \%$ do total, sendo eles, as atividades de uso rural $(26,28 \%)$ seguido dos usuários públicos (17,47\%); soluções alternativas 1 $(11,20 \%)$ a qual representa modalidade de abastecimento público de água por meio de fontes subterrâneas realizado a partir de poços comunitários e coletivos; irrigantes $(11,12 \%)$ e uso industrial $(10,93 \%)$.

Entre as finalidades, as mais expressivas são sanitário $(23,33 \%)$ e abastecimento público $(19,56 \%)$, enquanto que as demais apresentamuma distribuição mais homogênea.

Observa-se que os principais usos água são decorrentes da captação subterrânea, seguida de lançamento em soloe captação superficial. Nota-se dessa forma que as águas subterrâneas são as principais fontes de abastecimento destinadas às diversas atividades realizadas nas bacias dos Rios Aguapeí e Peixe. Os dados demonstram a importância das águas subterrâneas na região abrangendo tanto o meio rural quanto o meio urbano. Isso vem em direção a Kohori e Pirolli (2018) os quais descrevem que os municípios da região de Adamantina (médio Peixe) tiveram suas sedes construídas no espigão-divisor de águas dos rios Aguapeí e Peixe, ocupando, portanto, nascentes de córregos afluentes de ambos os rios. Nesse aspecto pode se observar a preferência pela utilização de águas subterrâneas em comparação às fontes superficiais em função do processo de colonização da região que ocorreu em decorrência da expansão da rede ferroviária em direção ao rio Paraná e devido à oferta de águas pelos aquíferos na região, dessa maneira privilegiando as águas subterrâneas em relação às águas superficiais .

Segundo Canato et al. (2014) o Sistema Aquífero Bauru (SAB) representa uma das principais fontes de explotação de águas subterrâneas no Estado de São Paulo. Dentre os 462 municípios paulistas que são abastecidos, parcial ou integralmente, por água subterrânea, aproximadamente $59 \%$ captam água do $\mathrm{SAB}$, sendo que em $88 \%$ deles o abastecimento é feito exclusivamente por água subterrânea. $\mathrm{O}$ fato deste tipo de uso se destacar se deve principalmente aos menores custos relacionados à captação e tratamento da água e a distância dos locais onde seria obtida a água proveniente de rios ou córregos, que apesar disso, ainda mantêm disponibilidade segura na região. Portanto a utilização dos recursos hídricos subterrâneos está relacionada à sua disponibilidade devido à presença de extensos mananciais subterrâneos fazendo o uso em sua maioria do SAB. O lançamento em solo geralmente é realizado a partir do uso de fossas sépticas e valas de infiltração ou sumidouros e apresentam relação com a distância dos sistemas de captação de esgoto que se encontram centralizados nas áreas urbanas, servindo assim, são utilizados como alternativa mais viável de eliminação de efluentes sejam domésticos ou gerados a partir de alguma atividade econômica desenvolvida em áreas periurbanas e rurais.

As informações denotam que a água é utilizada em áreas rurais visando a fornecimento para o abastecimentoe o saneamento, direcionando dessa forma para o consumo humano, aspectos que concordam com as observações de Lourencetti et al. (2015). 
Revista Brasileira de Geografia Física v.14, n.04 (2021) 2172-2185.

\begin{tabular}{|c|c|c|c|c|c|c|c|c|}
\hline \multicolumn{3}{|c|}{ USO } & \multicolumn{3}{|c|}{ USUÁRIO } & \multicolumn{3}{|c|}{ FINALIDADE } \\
\hline Tipo & Quantidade & $\%$ & Tipo & Quantidade & $\%$ & Tipo & Quantidade & $\%$ \\
\hline $\begin{array}{c}\text { Captação } \\
\text { Subterrânea } \\
\end{array}$ & 1880 & 50,99 & Uso Rural & 969 & 26,28 & Sanitário & 860 & 23,33 \\
\hline Lançamento em solo & 618 & 16,76 & Público & 644 & 17,47 & Abast. Público & 721 & 19,56 \\
\hline Captação superficial & 260 & 7,05 & $\begin{array}{c}\text { Soluções } \\
\text { alternativas 1 }\end{array}$ & 413 & 11,20 & Irrigação & 294 & 7,97 \\
\hline $\begin{array}{c}\text { Lançamento } \\
\text { superficial }\end{array}$ & 239 & 6,48 & Irrigante & 410 & 11,12 & Hidroagrícola & 242 & 6,56 \\
\hline Barramento & 152 & 4,12 & Industrial & 403 & 10,93 & $\begin{array}{l}\text { Adequação obras } \\
\text { saneamento }\end{array}$ & 144 & 3,91 \\
\hline Travessia aérea & 143 & 3,88 & Aquicultor & 272 & 7,38 & Água Mineral & 141 & 3,82 \\
\hline Lançamento em rede & 120 & 3,25 & Criador & 148 & 4,01 & Dessedentação & 134 & 3,63 \\
\hline $\begin{array}{c}\text { Travessia } \\
\text { intermediária }\end{array}$ & 66 & 1,79 & Uso Urbano & 135 & 3,66 & $\begin{array}{c}\text { Passagem Rodovia } \\
\text { e Ferrovia }\end{array}$ & 101 & 2,74 \\
\hline $\begin{array}{c}\text { Reservação } \\
\text { Subterrâneo- } \\
\text { Superficial) } \\
\end{array}$ & 52 & 1,41 & Minerador & 97 & 2,63 & Controle de Erosão & 97 & 2,63 \\
\hline $\begin{array}{c}\text { Travessia } \\
\text { subterrânea }\end{array}$ & 34 & 0,92 & Loteador & 53 & 1,44 & Sanitário/industrial & 89 & 2,41 \\
\hline Canalização & 26 & 0,71 & Pecuarista & 50 & 1,36 & $\begin{array}{c}\text { Elevação Regular } \\
\text { de Nível }\end{array}$ & 76 & 2,06 \\
\hline $\begin{array}{l}\text { Extração de } \\
\text { minérios }\end{array}$ & 25 & 0,68 & $\begin{array}{l}\text { Concessionári } \\
\text { as distribuição }\end{array}$ & 17 & 0,46 & Industrial & 69 & 1,87 \\
\hline $\begin{array}{c}\text { Captação em } \\
\text { nascente }\end{array}$ & 20 & 0,54 & Outros & 13 & 0,35 & Mineração & 67 & 1,82 \\
\hline Desassoreamento & 19 & 0,52 & $\begin{array}{l}\text { Irrigação/ } \\
\text { Pecuária }\end{array}$ & 13 & 0,35 & Comércio/Serviço & 66 & 1,79 \\
\hline $\begin{array}{c}\text { Proteção de } \\
\text { leito/Margem }\end{array}$ & 11 & 0,30 & Comerciante & 12 & 0,33 & $\begin{array}{l}\text { Solu. alternat. } \\
\text { Abast. Priv. }\end{array}$ & 58 & 1,57 \\
\hline Captação em rede & 8 & 0,22 & $\begin{array}{l}\text { Aquicultor/ } \\
\text { Pecuária }\end{array}$ & 7 & 0,19 & $\begin{array}{c}\text { Dessedentação/ } \\
\text { Piscicultura }\end{array}$ & 58 & 1,57 \\
\hline $\begin{array}{l}\text { Extração de água } \\
\text { subterrânea }\end{array}$ & 6 & 0,16 & Avicultor & 7 & 0,19 & $\begin{array}{l}\text { Passag./tubul. } \\
\text { gas soduto,rede } \\
\text { água/es goto }\end{array}$ & 54 & 1,46 \\
\hline Travessia & 5 & 0,14 & $\begin{array}{l}\text { Irrigação/ } \\
\text { Aquicultor }\end{array}$ & 6 & 0,16 & Efluente Público & 53 & 1,44 \\
\hline Extração de areia & 1 & 0,03 & Condomínio & 5 & 0,14 & $\begin{array}{c}\text { Desassoreamento/ } \\
\text { limpeza }\end{array}$ & 40 & 1,08 \\
\hline $\begin{array}{l}\begin{array}{l}\text { Fonte (água } \\
\text { superficial) }\end{array} \\
\end{array}$ & 1 & 0,03 & Construtor & 5 & 0,14 & $\begin{array}{c}\text { Uso rural, exceto } \\
\text { irrigação }\end{array}$ & 37 & 1,00 \\
\hline $\begin{array}{c}\text { Lançamento em } \\
\text { cava }\end{array}$ & 1 & 0,03 & $\begin{array}{c}\text { Uso } \\
\text { Comunitário }\end{array}$ & 3 & 0,08 & $\begin{array}{c}\text { Regularização de } \\
\text { vazão }\end{array}$ & 37 & 1,00 \\
\hline Total & 3.687 & & $\begin{array}{c}\text { Soluções } \\
\text { alternativas 2 }\end{array}$ & 2 & 0,05 & Drenagem & 36 & 0,98 \\
\hline & & & Termoelétrica & 2 & 0,05 & $\begin{array}{l}\text { Doméstico em } \\
\text { residências }\end{array}$ & 33 & 0,90 \\
\hline & & & Empre. lavag. & 1 & 0,03 & Desvio & 31 & 0,84 \\
\hline & & & Hidroelétrica & 0 & 0,00 & Irrigação/Dessed. & 30 & 0,81 \\
\hline & & & Total & 3.687 & & Geração de energia & 23 & 0,62 \\
\hline & & & & & & $\begin{array}{l}\text { Solu. alternat. abast. } \\
\text { privado/industrial }\end{array}$ & 17 & 0,46 \\
\hline & & & & & & $\begin{array}{c}\text { Lazer/Recreaçãoe } \\
\text { Paisagismo }\end{array}$ & 16 & 0,43 \\
\hline & & & & & & $\begin{array}{c}\text { Irrigação/ } \\
\text { Piscicultura } \\
\end{array}$ & 14 & 0,38 \\
\hline & & & & & & Outras Finalidades & 11 & 0,30 \\
\hline & & & & & & $\begin{array}{c}\text { Sanitário/Rega de } \\
\text { Jardim }\end{array}$ & 8 & 0,22 \\
\hline & & & & & & $\begin{array}{l}\text { Umectação plantas } \\
\text { e compactação solo }\end{array}$ & 8 & 0,22 \\
\hline & & & & & & Uso urbano & 5 & 0,14 \\
\hline & & & & & & Proteção de Leito & 5 & 0,14 \\
\hline & & & & & & Combate incêndio & 3 & 0,08 \\
\hline & & & & & & $\begin{array}{l}\text { Adequação } \\
\text { Urbanística } \\
\end{array}$ & 3 & 0,08 \\
\hline & & & & & & Pesquisa & 3 & 0,08 \\
\hline & & & & & & $\begin{array}{c}\text { Solu. alternat. } \\
\text { transp. água }\end{array}$ & 1 & 0,03 \\
\hline & & & & & & $\begin{array}{l}\text { Piezômetro de } \\
\text { monitoramento }\end{array}$ & 1 & 0,03 \\
\hline & & & & & & Rega de Jardim & 1 & 0,03 \\
\hline & & & & & & Total & 3.687 & \\
\hline
\end{tabular}

Tabela 1. Quantidade e percentual de usos, usuários e, finalidades a partir de dados de outorgas cadastradas na área de abrangência do Comitê das bacias hidrográficas dos rios Aguapeí e Peixe (UGHRI's 20 e 21). 
Os resultados condizem com a realidade econômica da região, onde se destacam as lavouras de café, cana-de-açúcar e milho e a atividade de pecuária (SIGRH, 2020). As propriedades rurais contidas nas regiões dos Escritórios de Desenvolvimento Regional de Marília, Tupã e Dracena, em sua maior parte, detém áreas de até 50ha (CDRS, 2020), o que confere uma maior distribuição das outorgas nas áreas rurais dos municípios para atender aos diferentes usuários demonstrando que a estrutura fundiária regional colabora para a dispersão dos usos os quais são realizados visando a autonomia do fornecimento de água e posteriormente a busca por meios de destinação final dos efluentes gerados. Os valores descritos para as soluções alternativas 1 podem estar relacionados aos investimentos dos próprios produtores rurais, mas também da implantação de poços comunitários e coletivos provenientes do estímulo gerado a partir do programa estadual de microbacias hidrográficas 1 o qual foi desenvolvido em diferentes sub-bacias hidrográficas dos rios Aguapeí e Peixe. De acordo com Clemente (2017) o programa implementou ações entre elas a implantação de poços para o abastecimento de água a grupos de proprietários.

Outros usuários como os aquicultores, avicultores, industriais, loteadores, irrigantes, pecuaristas, mineradores, uso rural em geral e dentre outros também regularizaram suas outorgas para a finalidade de sanitário. Nota-se nesse caso que esse tipo de regularização se torna importante não só usuários que atendem em sua grande maioria a população urbana obter a outorga, mas também a população e usuários do meio rural, pois assim os cursos d'água e lençóis freáticos não são intensamente impactados com os efluentes gerados.

Entre as finalidades, sanitário e abastecimento público, se destaca a participação das empresas ligadas aos serviços de captação, tratamento e distribuição de água e captação, tratamento e despejo de esgoto. Dos 51 municípios analisados 32 possuem o sistema de água e esgoto operados pela Companhia de Saneamento Básico do Estado de São Paulo (SABESP), enquanto que outros 19 possuem serviços autônomos de água e esgoto. Sendo assim, 62,7\% dos municípios apresentam sistema de água operado pela SABESP e 37,3\% possuem serviços autônomos de água e esgoto (CBHAP, 2020). Além dessas empresas, os valores da finalidade saneamento também estão relacionadas a proeminência da utilização das águas subterrâneas na região, uma vez que seu uso é realizado buscando se garantir a diluição e condução de efluentes.

Apesar do relevante número de outorgas emitidas, existe dificuldade em se afirmar que todos os usuários estejam regularizados, fato que pode comprometer a gestão dos recursos hídricos na medida em que o órgão regulador, no caso, o DAEE, não dispõe de informações sobre a localização e a potencial influência dos usos sobre os recursos hídricos.

Uma das explicações para este problema é que os procedimentos para a solicitação de outorgas são burocráticos, cartoriais e onerosos, implicando no dispêndio de recursos e tempo para essa finalidade. Mas, além disso, muitos dos usuários de recursos hídricos receiam que na medida em que sejam identificados pelas autoridades em relação ao uso da água, possam ser também suscetíveis a frequente e rígida fiscalização.

A necessidade da aprovação de órgãos públicos que envolvam questões ambientais, como a CETESB, pode ser outro aspecto que interfira na regularização de outorgas. Nesse caso, devido ao fato que o usuário por muitas vezes se receie por não deter todos os quesitos necessários regularizados, sejam estruturais ou documentais. Dessa maneira a evolução da outorga de direito de uso da água como instrumento de gestão e como base para o suprimento de informações para os demais instrumentos de Política Estadual de Recursos Hídricos se torna prejudicado.

\section{Distribuição das outorgas}

De acordo com os dados obtidos pode se observar que o valor médio de IDHM nos municípios em ambas as unidades de gerenciamento é de 0,733 (Tabela 4) o que lhes garante, segundo PNUD (2020), um alto grau de desenvolvimento humano. Isso reflete na capacidade regional em investimentos para a obtenção de água visando a produção e comercialização de bens e insumos. 


\begin{tabular}{|c|c|c|c|c|c|c|}
\hline \multicolumn{7}{|c|}{ UGRHI 20 - Aguapeí } \\
\hline Município & População & $\begin{array}{c}\text { Renda per } \\
\text { capita }\end{array}$ & IDHM & Área & $\begin{array}{c}\text { PIB per capita } \\
\text { (R\$/hab/ano) }\end{array}$ & $\begin{array}{c}\text { Número de } \\
\text { outorgas }\end{array}$ \\
\hline Álvaro de Carvalho & 4.650 & 2,10 & 0,688 & 153,66 & 9.772 & 30 \\
\hline Arco-Íris & 1.925 & 2,00 & 0,722 & 264,90 & 27.756 & 42 \\
\hline Clementina & 7.065 & 3,40 & 0,725 & 168,59 & 26.394 & 71 \\
\hline Dracena & 43.258 & 2,00 & 0,776 & 487,69 & 24.326 & 256 \\
\hline Gabriel Monteiro & 2.708 & 1,70 & 0,763 & 138,68 & 21.292 & 46 \\
\hline Getulina & 10.765 & 2,20 & 0,717 & 676,76 & 15.020 & 59 \\
\hline Guaimbê & 5.425 & 2,00 & 0,728 & 217,81 & 12.752 & 41 \\
\hline Herculândia & 8.696 & 2,40 & 0,727 & 364,25 & 28.896 & 75 \\
\hline Iacri & 6.419 & 2,00 & 0,733 & 321,95 & 23.151 & 80 \\
\hline Júlio Mesquita & 4.430 & 1,80 & 0,716 & 128,18 & 10.824 & 19 \\
\hline Lucélia & 19.882 & 1,70 & 0,752 & 314,81 & 18.543 & 89 \\
\hline Luiziânia & 5.030 & 2,00 & 0,702 & 166,58 & 12.438 & 24 \\
\hline Monte Castelo & 4.063 & 1,90 & 0,741 & 233,55 & 21.414 & 75 \\
\hline Nova Guataporanga & 4.063 & 2,10 & 0,726 & 34,16 & 12.789 & 15 \\
\hline Nova Independência & 3.068 & 3,50 & 0,735 & 265,03 & 33.785 & 51 \\
\hline Pacaembu & 13.226 & 2,00 & 0,725 & 339,38 & 14.217 & 85 \\
\hline Panorama & 15.539 & 2,00 & 0,722 & 353,10 & 8.376 & 76 \\
\hline Parapuã & 10.844 & 2,40 & 0,737 & 366,66 & 26.860 & 141 \\
\hline Paulicéia & 6.339 & 2,50 & 0,711 & 374,09 & 81.401 & 82 \\
\hline Piacatu & 5.287 & 1,70 & 0,732 & 232,49 & 17.357 & 51 \\
\hline Pompéia & 19.964 & 3,80 & 0,786 & 784,67 & 49.748 & 53 \\
\hline Queiroz & 2.808 & 2,60 & 0,715 & 234,91 & 133.036 & 18 \\
\hline Quintana & 6.004 & 2,40 & 0,732 & 318,94 & 23.500 & 52 \\
\hline Rinópolis & 9.935 & 2,30 & 0,723 & 358,48 & 21.670 & 96 \\
\hline Salmourão & 4.818 & 1,80 & 0,719 & 172,93 & 13.440 & 35 \\
\hline Santa Mercedes & 2.831 & 1,90 & 0,739 & 166,75 & 20.832 & 29 \\
\hline Santópolis do Aguapeí & 4.277 & 1,60 & 0,740 & 128,03 & 13.067 & 18 \\
\hline São João do Pau D'Alho & 2.103 & 2,40 & 0,750 & 117,67 & 22.693 & 45 \\
\hline Tupã & 63.476 & 2,00 & 0,771 & 627,99 & 25.424 & 332 \\
\hline Tupi Paulista & 14.269 & 2,00 & 0,769 & 244,77 & 17.119 & 115 \\
\hline Vera Cruz & 10.769 & 2,10 & 0,754 & 247,72 & 11.229 & 129 \\
\hline Total & 182.229 & - & - & $7.884,70$ & -- & 2.330 \\
\hline Média & 9.336 & 2,20 & 0,732 & 290,49 & 26.358 & 75 \\
\hline
\end{tabular}

Tabela 2. Número total de outorgas e aspectos socioeconômicos dos municípios na Unidade de Gerenciamento de Recursos Hídricos do Estado de São Paulo número 20 (Aguapeí) e pertencentes ao CBHAP.

Foi possível se identificar entre os municípios estudados um total de 2.330 outorgas ocorrentes nos na UGRHI-20 e 1.357 outorgas nos municípios que compõem a UGRHI-21, Silva, F. B.; Queiroz, T. R.; Burkert, D.; Manzione, R.L. respectivamente, o que representa um número médio de outorgas por município da UGRHI de 75 e 68 , demonstrando que além de deter um número maior de municípios, a UGHRI-20 (Aguapeí) 
também tem número total e valor médio de outorgas superior (Tabelas 2 e 3 ).

Dentre os municípios estudados aqueles que se destacam pela maior quantidade de outorgas na UGRHI-20 são Tupã com 332 outorgas e Dracena com 256. Enquanto que na UGRHI-21 o município de Bastos apresenta um número de outorgas (376) superior aos demais. Juntos os três municípios concentram $26 \%$ das outorgas na área abrangida pelo comitê das bacias hidrográficas. Esses resultados apresentam forte relação com o modelo de regressão analisado.

\begin{tabular}{|c|c|c|c|c|c|c|}
\hline \multicolumn{7}{|c|}{ UGRHI 21 - Peixe } \\
\hline Município & População & $\begin{array}{l}\text { Renda per } \\
\text { capita }\end{array}$ & IDHM & Área & $\begin{array}{c}\text { PIB per capita } \\
\text { (R\$/hab/ano) }\end{array}$ & Número de outorgas \\
\hline Adamantina & 33.797 & 2,00 & 0,790 & 411,99 & 32.839 & 153 \\
\hline Alfredo Marcondes & 3.891 & 2,00 & 0,741 & 118,92 & 18.075 & 22 \\
\hline Bastos & 20.445 & 2,60 & 0,751 & 170,91 & 39.033 & 376 \\
\hline Borá & 805 & 2,80 & 0,746 & 118,95 & 100.030 & 17 \\
\hline Caiabu & 4.072 & 1,90 & 0,729 & 253,35 & 13.658 & 25 \\
\hline Emilianópolis & 3.020 & 2,00 & 0,727 & 225,17 & 18.741 & 12 \\
\hline Flora Rica & 1.752 & 2,10 & 0,727 & 224,71 & 22.168 & 23 \\
\hline Flórida Paulista & 12.848 & 2,10 & 0,715 & 524,14 & 13.293 & 82 \\
\hline Inúbia Paulista & 3.630 & 2,40 & 0,759 & 87,12 & 31.753 & 38 \\
\hline Irapuru & 7.789 & 2,40 & 0,712 & 214,46 & 10.226 & 94 \\
\hline Junqueirópolis & 18.726 & 2,60 & 0,745 & 582,57 & 47.068 & 161 \\
\hline Mariápolis & 3.916 & 2,00 & 0,718 & 186,54 & 13.781 & 39 \\
\hline Oriente & 6.097 & 2,30 & 0,770 & 218,67 & 15.119 & 37 \\
\hline Oscar Bressane & 2.537 & 2,00 & 0,749 & 222,13 & 32.076 & 26 \\
\hline Osvaldo Cruz & 30.917 & 1,90 & 0,762 & 248,04 & 29.902 & 111 \\
\hline Ouro Verde & 7.800 & 2,00 & 0,692 & 266,78 & 11.854 & 39 \\
\hline Pracinha & 2.858 & 1,70 & 0,696 & 63,05 & 7.310 & 19 \\
\hline Ribeirão dos Índios & 2.187 & 1,80 & 0,721 & 196,45 & 17.801 & 15 \\
\hline Sagres & 2.395 & 1,60 & 0,730 & 147,94 & 16.685 & 31 \\
\hline Santo Expedito & 2.803 & 1,70 & 0,732 & 94,47 & 10.972 & 37 \\
\hline Total & 161.682 & - & - & $4.576,34$ & - & 1.357 \\
\hline Média & 8.982 & 2,10 & 0,729 & 228,82 & 25.119 & 68 \\
\hline
\end{tabular}

Tabela 3. Número total de outorgas e aspectos socioeconômicos dos municípios na Unidades de Gerenciamento de Recursos Hídricos do Estadode São Paulonúmero 21 (Peixe)) e pertencentes ao CBHAP. 


\begin{tabular}{|c|c|c|c|c|c|c|}
\hline \multicolumn{7}{|c|}{ Valores totais e médios das UGRHI’s 20 e 21 } \\
\hline Município & População & $\begin{array}{c}\text { Renda per } \\
\text { capita }\end{array}$ & IDHM & Área & $\begin{array}{c}\text { PIB per capita } \\
\text { (R\$/hab/ano) }\end{array}$ & $\begin{array}{c}\text { Número de } \\
\text { outorgas }\end{array}$ \\
\hline Total & 432.425 & - & & $13.581,50$ & - & 3.687 \\
\hline Média & $\mathbf{9 . 2 0 1}$ & $\mathbf{2 , 1 6}$ & $\mathbf{0 , 7 3 3}$ & $\mathbf{2 6 6 , 3 0}$ & $\mathbf{2 5 . 8 6 3}$ & $\mathbf{7 2}$ \\
\hline
\end{tabular}

Tabela 4. Número total e médio de outorgas e valores totais e médios dos aspectos socioeconômicos dos municípios nas Unidades de Gerenciamento de Recursos Hídricos do Estado de São Paulo números 20 (Aguapeí) e 21 (Peixe) e pertencentes ao CBHAP.

Referente aos dados obtidos pode se observar que os conjuntos de variáveis que melhor se adequaram a descrição do número de outorgas nos municípios foram o LOG_PIB e LOB_POP de acordo com os valores de C-p e S (1,7 e 0,19686, respectivamente). $\mathrm{O}$ modelo também apresentou valores-p abaixo de 5\%, ou seja, os valores podem ser utilizados na equação de regressão.

Dessa maneira, o modelo determinado a partir dos resultados obtidos dos coeficientes de regressão foi:

$$
\begin{aligned}
& \text { LOG_OUT }=-2,09+0,512 \text { LOG_POP }+0,229 \\
& \text { LOG_PIB }
\end{aligned}
$$

A porcentagem que é explicada pelo modelo corresponde medida pelo $\mathrm{R}^{2}$ ajustado que foi de $69,1 \%$, no entanto, o $\mathrm{R}^{2}$ preditof oi de $70,3 \%$, mostrando que o modelo tem capacidade preditiva e não suportando as demais variáveis. Para Bruni (2008) o coeficiente de determinação $\left(R^{2}\right)$ equivalente a $70 \%$, esse valor ou, superior, é considerado característica de um bom ajuste.

Em relação ao modelo de regressão Manzione, Nava e Sartori (2020) descrevem que o uso de um modelo multivariado para os instrumentos de gestão em que auxilia a tomada de decisão quanto ao uso da água e fornece suporte aos instrumentos de gestão de recursos hídricos como ferramentas para o planejamento dos recursos hídricos. De acordo com isso, o atual modelo garantiu embasamento para contemplar os resultados encontrados na pesquisa e também demonstrar que um modelo de regressão linear múltiplo pode ser útil para determinar as variáveis independentes que explicam a variável dependente outorga envolvendo recurso hídrico. De acordo com o modelo foi possível verificar que conforme ocorre o aumento da população juntamente com a melhoria das condições econômicas nos municípios dessas duas bacias ocorre consequentemente o aumento do número de outorgas e que o aumento da população tem uma maior influência nesse crescimento do que o crescimento das condições econômicas. A análise visual do modelo quanto a normalidade dos resíduos e sua variância pode ser observada na Figura 2. De forma geral, os resíduos são considerados normais, distribuindo-se sob a linha reta azul e quanto ao seu histograma, conforme os gráficos à esquerda superior $(\mathrm{A})$ e inferior (B), respectivamente. A distribuição dos resíduos quando relacionados aos valores ajustados e aos valores de ordem de observação indicam uma variância constante, pois flutuam em torno de zero. Os resíduos dos valores ajustados variam entre 0,25 e $-0,25$ e os resíduos da ordem de observações representam o desvio padrão de 0,19 indicado nas estatísticas de ajuste, conforme mostram os gráficos à direita da Figura $2(\mathrm{C}$ e D) mostram, respectivamente.

Esses dados demonstram que o modelo gerado é considerado aceito. Essa descrição vem de encontro aos dados observados para os municípios de Dracena e Tupã, os quais se destacamem termos populacionais e de IDHM, sendo os dois aspectos socioeconômicos superiores aos dos demais municípios localizados na UGRHI-20. Valores de IDHM elevados representam uma maior capacidade em investimentos na produção e consequente capacidade de geração de renda repercutindo em melhoria de vida da população local. Dessa maneira a interação entre o número de habitantes e aspectos relacionados à qualidade de vida de suas populações, como por exemplo, a intensificação das atividades econômicas tende a promover o aumento no uso e na demanda de água visando o aumento da produção; na ampliação de serviços; para a geração de efluentes ou mesmo na intensificação de outras intervenções, como construção de pontes, instalação de travessias, as quais estarão associadas ao desenvolvimento local e com consequente incremento na quantidade de outorgas.

Outros fatores podem ter também influenciado os usuários de água a regularizarem seus poços, principalmente em relação ao uso rural e irrigantes. Um deles está ligado à disponibilização de linhas de crédito destinadas para construção de poços artesianos e modernização de equipamentos de irrigação. As linhas integram o projeto "Agricultura Irrigada Paulista”, do Fundo de Expansão do Agronegócio 
Paulista (FEAP), e beneficiaram produtores, cooperativas e associações. $O$ financiamento incentivava a construção de poços, a aquisição de acessórios, equipamentos de irrigação e outros produtos, ações que garantiam a maior eficiência no uso dos recursos hídricos e também o produtor podia incluir no financiamento as despesas com procedimentos necessários para obter a outorga d'água, georreferenciamento e processo de

A

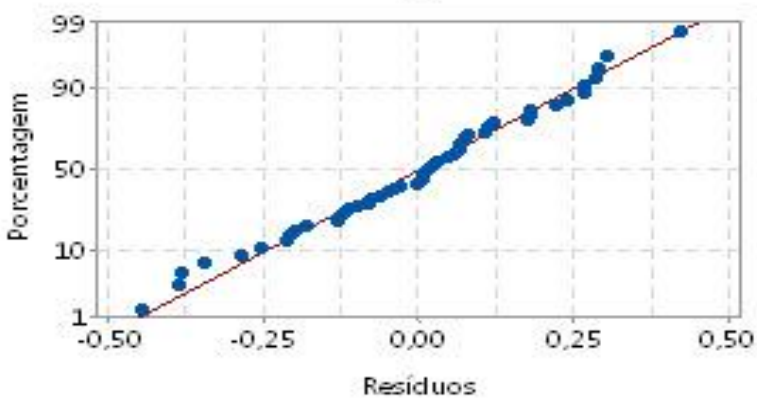

B

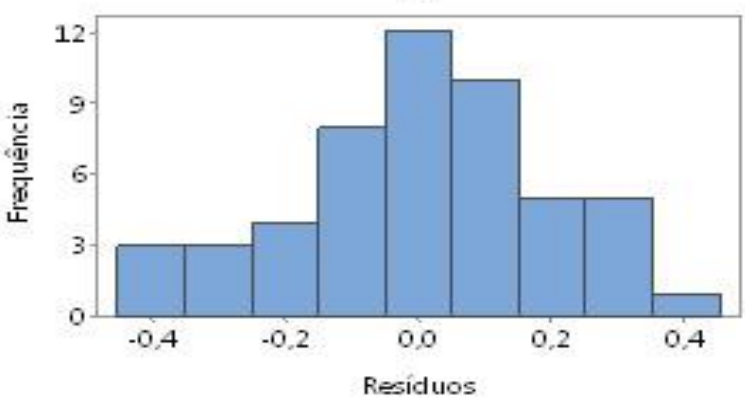

licenciamento ambiental. $\mathrm{Na}$ ocasião existia a exigência por parte dos órgãos financiadores da regularização dos usos da água para que os tomadores pudessem ser contemplados com o financiamento. Dessa maneira a busca pelos investimentos serviram de estímulo à solicitação de outorgas e consequentemente fizeram com que os dados de ocorrência desses usuários se demonstrassem proeminentes.
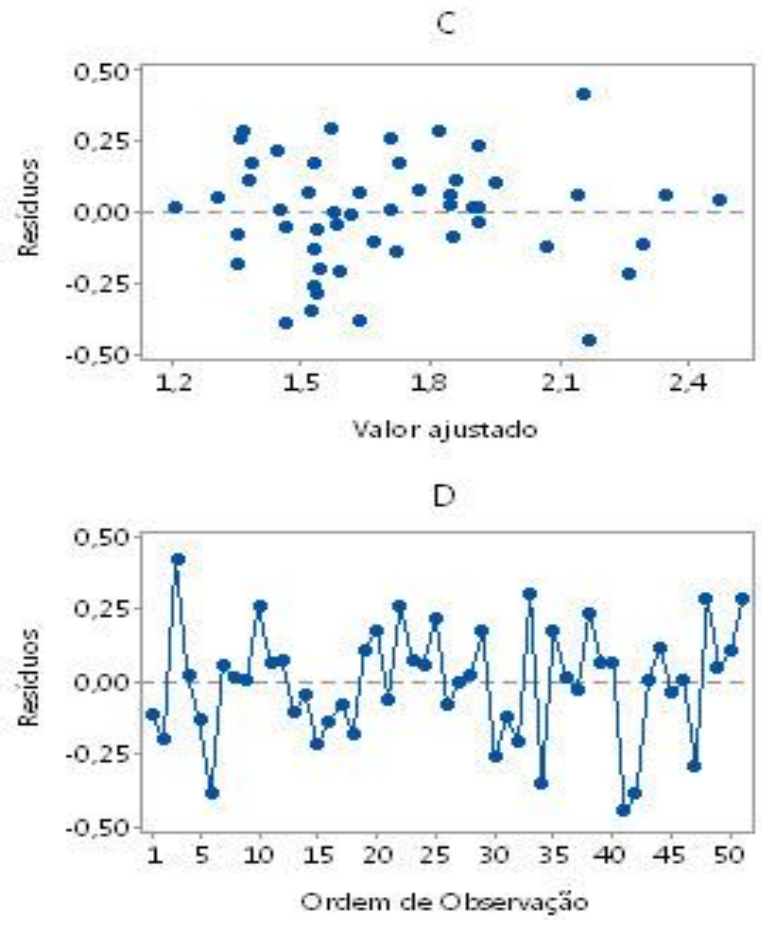

Figura 2 - Gráficos de análise de resíduo. Fonte: Próprio Autores.

O outro fator também está relacionado a uma política pública de desenvolvimento do agronegócio que foi o Programa Estadual de Microbacias Hidrográficas 1. De acordo com Neves Neto e Clemente (2014) o programa além de dispor de recursos para investimentos de produção agropecuária buscou investir na construção de poços para o abastecimento de água a grupos de proprietários das microbacias. Uma vez aprovados os recursos para instalação dos poços, a partir dos investimentos provenientes do programa, os mesmos deveriam ser regularizados. Esses dois aspectos demonstram que a geração de políticas públicas pode contribuir com o processo de indução do ordenamento dos recursos hídricos, não só somente a partir da exigência da aplicação de mecanismos de comando e controle, como a outorga do direito do uso da água, mas também a partir da aplicação de ações que estimulem economicamente os potenciais usuários dos recursos hídricos que em contrapartida tenham que Silva, F. B.; Queiroz, T. R.; Burkert, D.; Manzione, R.L. atender as exigências legais para a sua execução.

Nos municípios de Bastos, Dracena e Tupã, que são aqueles que demonstram os maiores números de outorgas, se destacam usos, usuários e finalidades com perfis similares ao do restante da área de abrangência do CBHAP (Tabela 5). Mas, diferentemente de Dracena e Tupã, Bastos, que é o município que concentra o maior número de outorgas em relação aos demais municípios na UGRHI-21, apresenta valores de população e de IDHM inferiores aos de alguns de seus vizinhos.

Apesar de o município ter estado sujeito aos mesmos programas de investimentos públicos voltados à expansão e aprimoramento do agronegócio que Dracena e Tupã, este ainda se destaca na região em função do arranjo econômico local o qual é baseado na avicultura de postura. De acordo com a Secretaria de Agricultura e Abastecimento do Estado de São Paulo (2020) o município de Bastos foi o maior produtor de ovos 
no Estado, representando 36\% da produção total no ano de 2018.

Os usuários outorgados no município de Bastos estão predominantemente no meio rural e direcionados para a criação de aves de postura. São 111 usuários que considerados como criadores e mais 112 usuários que desempenham atividades de uso rural, dos quais uma grande parcela está ligada a atividade da avicultura de postura. Além disso, dentre as finalidades de uso das águas no município se destacam os fins sanitários com um total de 218 outorgas e 82 para dessedentação de animais os quais estão correlacionados com a regulação em propriedades rurais, em especial granjas de criação de aves poedeiras. Pode se observar que essa cadeia de produção funciona de forma distribuída em diversas unidades produtivas ligadas direta e indiretamente a essa atividade principal, dispersando dessa maneira o uso da água dentro do município. Existe outra hipótese para que o número de outorgas em Bastos tenha sido superior, e, nesse caso, também está ligada à atividade da produção de ovos.

Os produtores ao buscarem instituições financeiras para a obtenção de créditos vislumbrando investimentos para aumento da produção verificam a necessidade da atualização em termos de regularização ambiental, como o licenciamento ambiental e a outorga do direito do uso da água, como requisitos básicos para aprovação de crédito. Sendo assim, o crescimento da atividade econômica pode ter refletido no aumento da regularização em termos gerais.

De forma geral pode se observar que o desenvolvimento e aplicação de políticas públicas,

\begin{tabular}{|c|c|c|c|c|c|c|c|c|c|c|c|}
\hline \multicolumn{4}{|l|}{ SO } & \multicolumn{4}{|l|}{ Usuários } & \multicolumn{4}{|c|}{ Finalidade } \\
\hline Tipo & Bastos & Dracena & Tupã & Tipo & Bastos & Dracena & Tupã & Tipo & Bastos & Dracena & Tupã \\
\hline Captação subterrânea & 215 & 143 & 151 & Uso rural & 112 & 70 & 75 & Sanitar & 218 & 111 & 157 \\
\hline Lançamento em solo & 111 & 50 & 58 & Público & 16 & 53 & 33 & Ab.publ & 6 & 23 & 20 \\
\hline Lançamento superf. & 9 & 14 & 34 & Solalt 1 & 76 & 46 & 62 & Hidroag & 4 & 22 & 66 \\
\hline Lançamento em rede & 13 & 9 & 26 & Industrial & 25 & 27 & 37 & San/Ind & 14 & 17 & 15 \\
\hline Travessia aérea & 3 & 7 & 1 & Aquicultor & 7 & 17 & 71 & Irrigac & 6 & 15 & 5 \\
\hline Captação superficial & 8 & 6 & 29 & Irrigante & 6 & 16 & 4 & Passage & 1 & 13 & 3 \\
\hline Travessia intermed. & 0 & 6 & 2 & Loteador & 0 & 10 & 0 & Salabpr & 3 & 12 & 15 \\
\hline Reserva (sub-superf) & 0 & 5 & 1 & Pecuarista & 2 & 7 & 6 & Pasduto & 2 & 6 & 0 \\
\hline Desas soreamento & 0 & 4 & 1 & Uso urbano & 10 & 4 & 24 & Dessed & 82 & 5 & 8 \\
\hline Travessia subterrânea & 0 & 4 & 0 & Construtor & 0 & 3 & 0 & Elevniv & 6 & 5 & 7 \\
\hline Barramento & 9 & 3 & 22 & Comerciante & 0 & 1 & 5 & Industr & 4 & 5 & 8 \\
\hline Canalização & 4 & 2 & 3 & Irrig/pecu & 0 & 1 & 2 & Ds/Limp & 0 & 4 & 0 \\
\hline Travessia & 0 & 2 & 0 & Outros & 0 & 1 & 0 & Ef.publ & 1 & 4 & 4 \\
\hline Captação em rede & 0 & 1 & 2 & Avicultor & 7 & 0 & 0 & Irr/Des & 1 & 2 & 2 \\
\hline Extração minérios & 2 & 0 & 2 & Criador & 111 & 0 & 7 & Laz/Pai & 2 & 2 & 1 \\
\hline Proteção de leito & 2 & 0 & 0 & Minerador & 4 & 0 & 6 & Rural & 7 & 2 & 5 \\
\hline & & & & & & & & Umecs & 0 & 2 & 0 \\
\hline & & & & & & & & Drenage & 2 & 1 & 2 \\
\hline & & & & & & & & Irr/Pis & 0 & 1 & 0 \\
\hline & & & & & & & & Outros & 0 & 1 & 0 \\
\hline & & & & & & & & Regvaz & 1 & 1 & 2 \\
\hline & & & & & & & & San/Rjd & 0 & 1 & 1 \\
\hline & & & & & & & & Urbano & 0 & 1 & 0 \\
\hline & & & & & & & & Cerosao & 2 & 0 & 1 \\
\hline & & & & & & & & Comerci & 0 & 0 & 1 \\
\hline & & & & & & & & Miner & 4 & 0 & 6 \\
\hline & & & & & & & & Prleito & 2 & 0 & 0 \\
\hline & & & & & & & & Pz.moni & 1 & 0 & 0 \\
\hline & & & & & & & & Sa1/Ind & 7 & 0 & 3 \\
\hline
\end{tabular}

Tabela 5. Númerode usuários, finalidade de usoe usos a partir de dados de outorgas nos municípios de Bastos,

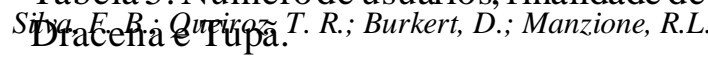


principalmente aquelas voltadas ao incremento produtivo, mas baseadas em investimentos financeiros, podem servir como meio de estímulo à regularização ambiental.

Do ponto de vista da análise do sistema de outorgas como fonte de informação pode se verificar dois pontos que trazem dificuldades para essa utilização. A primeira está relacionada com as classificações utilizadas pelo DAEE. Tais classificações eventualmente apresentam sobreposições que dificultam a análise dos dados e por consequência a sua interpretação. Como no caso dos usuários: usuário rural; avicultor; criador; pecuarista.

Pode se observar que em determinadas situações um mesmo usuário, por exemplo, um produtor de aves, pode ser indicado em todas as classificações, mas nesse caso, the cabe a alternativa de escolher apenas uma. Dessa forma, diversos usuários podem selecionar a classificação que lhes acredita ser a mais coerente, mas para fins de um levantamento mais preciso para o processo de regulação a informação pode ser perdida. $\mathrm{O}$ outro ponto está relacionado ao fato que a indicação é realizada pelo solicitante, dessa forma, os procedimentos adotados não garantem que o conhecimento a respeito das classificações seja o mesmo pelos diferentes solicitantes.

Acredita-se que a adequação do sistema, provavelmente a partir do SOE, possa garantir um melhor ordenamento e padronização dos dados. A utilização de uma plataforma mais intuitiva e a aplicação de uma sistemática mais linear poderão garantir a obtenção de dados de forma mais adequada para a posterior edição de dados facilitando assim a sua consequente análise.

Dessa maneira, o sistema de outorgas representa uma potencial ferramenta de geração de informações e que pode colaborar com a instrumentalização do gerenciamento dos recursos hídricos quando incorporada à sistemas de informações.

\section{Conclusões}

As outorgas nos municípios que compõem a área de abrangência do Comitê das Bacias Hidrográficas dos rios Aguapeí e Peixe estão relacionadas principalmente ao uso de águas subterrâneas em áreas rurais. Nos três municípios (Bastos, Dracena e Tupã) concentram 26\% das outorgas analisadas.

O aumento IDHM e da população, concomitantemente, estimulam o crescimento do número de outorgas.

A implementação de políticas públicas de investimentos para auxílio da produção agropecuária colabora para o aumento da regularização do uso da água.

\section{Agradecimentos}

À Suraya Modaelli e ao Emílio Carlos Prandi do DAEE(Departamento de Águas e Energia Elétrica) pela colaboração para a realização dessa pesquisa.

\section{Referências}

Bruni, A.L., 2008. Estatística aplicada à gestão empresarial. 2 ed. ATLAS, São Paulo.

Calado, T.O., Sobral, M.C., Cardoso, A.S., Marques, E.A.T., 2020. Planos diretores na articulação da gestão de recursos hídricos com o uso do solo no entorno de reservatónios. Revista Brasileira de Geografia Física [online] 13.

Disponível: https://doi.org/10.26848/rbgf.v13.3.p958-

972. Acesso: 20 jun. 2020.

Canato, H.M, Conceição, F.T., Hamada, J. Moruzzi, R.B., Navarro, G.R.B., 2014. Caracterização hidrogeoquímica do aquífero Adamantina na área urbana de Bauru, SP. Ciência \& Engenharia 2, 39-47.

CBH-AP. Comitê das Bacias Hidrográficas dos Rios Aguapeí e Peixe, 2016. Plano de Bacia das UGRHIs 20 e 21. São Paulo.

CDRS. Coordenadoria de Desenvolvimento Rural Sustentável, 2020. Levantamento censitário de unidades de produção agrícola no Estado de São Paulo - Dados Consolidados Regionais 2016/2017. Disponível: http://www.cdrs.sp.gov.br/projetolupa/dadosre gionais 1617.php. Acesso em: 10/09/2020.

Clemente, E.C. 2017. Análise dos resultados do programa de microbacias hidrográficas (fase i) na promoção do desenvolvimento rural na região de Jales-SP. Boletim Gáucho de Geografia, 44, 1-2.

DAEE. Departamento de Água e Energia Elétrica, 2019. Pesquisa de dados dos Recursos Hídricos do Estado de São Paulo. São Paulo.

Gazola, S., 2002. Construção de um modelo de regressão para avaliação de imóveis. Dissertação (Mestrado). Florianópolis, UFSC.

Godoy, M.C.T., 1999. Estudo hidrogeológico das zonas não saturada e saturada da formação Adamantina em Presidente Prudente - SP. Tese (Doutorado). São Paulo, USP.

Grizzetti, B., Lanzanova, D., Liquete, C., Reynaud, A., Cardoso A., 2016. Assessing water ecosystem services for water resource management. Environmental Science \& Policy [Online] 61. Disponível: 
https://doi.org/10.1016/j.envsci.2016.04.008. Acesso: 20 mai. 2020.

Hassan, D., Bano, R., Burian, S.J., Ansari, K., 2017. Modeling water demand and supply for future water resources management. International Journal of Scientific \& Engineering Research 8, 1745-1750.

Kohori, C.B.; Pirolli, E.L., 2018. Dinâmica do uso da terra nas áreas de preservação permanente do alto curso da bacia do ribeirão dos ranchos Adamantina/SP. Revista Formação [Online] $25 . \quad$ Disponível: https://doi.org/10.33081/formacao.v25i46.553. Acesso: 15 ago. 2020.

Lourencetti, J., Prates, M.M., Burkert, D., 2015. Perfil da qualidade das águas de poços em Adamantina - SP, Brasil. Nucleus 12, 7-22.

Manzione, R. L., Nava A., Sartori, M. M. P., 2020. Modelo híbrido de oscilação de níveis freáticos a partir de diferentes variáveis ambientais. Revista Brasileira de Geografia Física [Online] 13. Disponível: https://doi.org/10.26848/rbgf.v13.3.p12311247. Acesso: 10 jul. 2020.

MINITAB, 2019. Visão geral para a melhor regressão de subconjuntos. Disponível: https://support.minitab.com/en-us/minitabexpress/1/help-and-how-to/modelingstatistics/regression/how-to/bestsubsets/before-you-start/overview/. Acesso: 22 fev. 2020.

Montgomery,D.C.; Runger, G.C., 2008. Estatística aplicada e probabilidade paraengenheiros, 2 ed. LTC, Rio de Janeiro.

Morettin, P.A.; Bussab, W.O., 2012. Estatística básica, 7 ed. SARAIVA, São Paulo.

Neves Neto, C.C.; Clemente, E.C., 2014. Análise da atuação do programa estadual de microbacias em São Paulo em suas duas fases (I e II). Revista do Departamento de Geografia 27, 147-169.

Nunes, D. B.; Barros Neto, J. P.; Freitas, S. M., 2019. Modelo de regressão linear múltipla para avaliação do valor de mercado de apartamentos residenciais em Fortaleza, CE. Ambiente Construído [Online] 19. Disponível: http://www.repositorio.ufc.br/ri/handle/riufc/4 8682. Acesso: 14 jul. 2020.
Piazi, J.; Lopes, F.A.; Ruchkys, U.A., 2018. Qualidade das águas e outorgas superficiais no médio rio das Velhas, Minas Gerais, Brasil. Caderno de Geografia [online] 28. Disponível: https://doi.org/10.5752/P.2318-

2962.2018v28n55p828-844. Acesso: 23 jul. 2020.

PNUD. PROGRAMA DAS NAÇÕES UNIDAS PARA O DESENVOLVIMENTO, 2020. O que é o IDHM.

Rocha, P.C., Santos, A.A., 2018. Análise hidrológica em bacias hidrográficas. Mercator (Fortaleza) [online] 17. Disponível: https://doi.org/10.4215/rm2018.e17025.

Acesso: 17 jul. 2020.

SAA. Secretaria de Agriculturae Abastecimento do Estado de São Paulo, 2020. Bastos é disparado o principal produtor de ovos paulista: são 5 bilhões por ano. Disponível: https://www.agricultura.sp.gov.br/noticias/bast os-e-disparado-o-principal-produtor-de-ovospaulista-sao-5-bilhoes-por-ano/. Acesso: 11 set. 2020.

Santos, N.B.C., Santos, R.H.G., Silva, R.F., 2018. Aplicação da Análise Multivariada e da Resolução CONAMA 357/2005 para Análise da Qualidade de Água em Rios de Pernambuco. Revista Brasileira de Geografia Física [online] 11.

Disponível: https://doi.org/10.26848/rbgf.v11.5.p18591875. Acesso: 13 jun. 2020.

SÃO PAULO, 1994. Lei $\mathrm{n}^{\circ}$ 9.034, de 04 de Dezembro.

SIGRH. Sistema Integrado de Gerenciamento de Recursos Hídricos do Estado de São Paulo, 2020. Apresentação CBH-AP. São Paulo.

UNESCO. Organização das Nações Unidas para a Educação, a Ciência e a Cultura, 2015. Água para um mundo sustentável. Perugia, Itália. 